\title{
IMPLICAÇÃO NO "NOVO" CÓDIGO FLORESTAL EM UMA UNIDADE FAMILIAR DA COMUNIDADE EXTRATIVISTA MONTE SIÃO - SÃO DOMINGOS DO CAPIM(PA)
}

\author{
Marcelo Augusto Machado Vasconcelos ${ }^{(a)}$, Cassiano Moraes Guerreiro ${ }^{(b)}$, Paulo Celso Santiago \\ Bittencourt $^{(\mathrm{c})}$, Ravena Ferreira de Figueiredo ${ }^{(\mathrm{d})}$ \\ (a) Docente da Faculdade de Tecnologia em Geoprocessamento, UFPA, vasconcelos@ufpa.br \\ ${ }^{(b)}$ Discente da Faculdade de Tecnologia em Geoprocessamento, UFPA, cassianoguerreiro7@ gmail.com \\ ${ }^{(c)}$ Docente da Faculdade de Tecnologia em Geoprocessamento, UFPA, paulocsbit@gmail.com

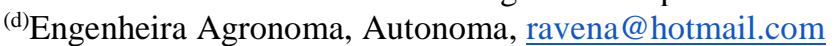

Eixo: Uso e ocupação das terras e legislação ambiental

\begin{abstract}
Resumo
Na comunidade extrativista Monte Sião o modo de vida de sua população estão intimamente ligados ao uso dos recursos naturais. De modo geral, as famílias combinam atividades extrativistas e de produção. Desperta-se a curiosidade de querer entender quais são as delimitações de uso dos recursos naturais em relação ao Novo Codigo Florestal( NCF). Assim, este trabalho tem por objetivo estudar o NCF e suas implicações em uma unidade familiar de várzea. Para alcance deste artigo utilizamos entrevistas abertas, semiestruturadas e não aleatórias às unidades familiares essas informações foram correlacionada com o NCF. Conclui-se que há um desacordo entre o NCF em relação à situação socioeconômica e ambiental, visto que repor área de RL e manter APP implica em perdas produtivas e que as restrições legais não têm sido suficientes para garantir a manutenção das florestas, uma vez que a maioria das unidades familiares já ultrapassou em $20 \%$ o limite de desmatamento autorizado.
\end{abstract}

Palavras chave: Conservação da natureza; Lei ambiental; Uso da terra; Produção.

\section{Introdução}

Desde o início da formação da comunidade extrativista Monte Sião, o modo de vida e a sobrevivência de sua população estão intimamente ligados ao manejo e uso dos recursos naturais (florestais, água, solo, dentre outros). De modo geral, as famílias combinam atividades extrativistas e de produção. A especialização em atividades extrativistas ou de produção nas localidades depende da oferta de recursos naturais, necessidade de subsistência e oportunidades de mercado.

Por outro lado, na legislação ambiental houve várias modificações feitas em relação no que diz respeito às "melhorias" dos recursos naturais por meio do Código Florestal Brasileiro (CFB). O projeto de Lei 1.876/99, que propunha alterações substanciais no antigo código florestal, (Lei 4.771/65), tramitou pelo Congresso Nacional sofrendo diversas modificações em seu texto, processo este que foi concluído com a sanção presidencial da Lei 12.651/2012 (OLIVEIRA; BONIN, 2011). 
$\mathrm{O}$ então NCF resultou em uma Lei que tem a função de dar o direcionamento das políticas públicas relativas ao uso e proteção da vegetação nativa do Brasil. Prates (2014) enfatiza que, dentre as principais mudanças que o NCF traz, destaca-se a criação do Programa de Regularização Ambiental (PRA), com vista a desburocratizar a legalização dos produtores de terra firme e extrativistas em desacordo com a lei, e novos critérios para o cômputo das Áreas de Preservação Permanente (APP) e Reserva Legal (RL). Esses dois termos alcançaram notoriedade maior, devido às áreas serem importantes mecanismos de preservação ambiental, mas, ao mesmo tempo, poderem limitar a expansão da atividade agropecuária e extrativista (PRATES, 2014). Neste particular, a Lei 12.651/2012 apresenta inovações que permitem o aumento da área disponível para as atividades econômicas, ou, sob outra ótica, diminuem as exigências territoriais para regularização ambiental (VIANA, 2011).

Para os efeitos da lei $\mathrm{n}^{\circ}$ 12.651, de 25 de maio de 2012 nos termos do Artigo 1, §2, inciso II, da Medida Provisória $n^{\circ} 2.166-67 / 01$ que alterou o código florestal (Lei № 4771/65), entende-se por:

II - APP: área protegida, coberta ou não por vegetação nativa, com a função ambiental de preservar os recursos hídricos, a paisagem, a estabilidade geológica e a biodiversidade, facilitar o fluxo gênico de fauna e flora, proteger o solo e assegurar o bem-estar das populações humanas;

III - RL: área localizada no interior de uma propriedade ou posse rural, delimitada nos termos do art. 12, com a função de assegurar o uso econômico de modo sustentável dos recursos naturais do imóvel rural, auxiliar a conservação e a reabilitação dos processos ecológicos e promover a conservação da biodiversidade, bem como o abrigo e a proteção de fauna silvestre e da flora nativa (BRASIL, 2012).

O presente trabalho tem por objetivo analisar as implicações do NCF no uso da terra em ecossistema de várzea relacionadas às atividades produtivas na Comunidade Extrativista Monte Sião localizada no município de São Domingos do Capim na Região Nordeste do Estado do Pará.

\section{Material e Métodos}

A construção da pesquisa foi dada a partir de fontes formais no código florestal, possuindo caráter cientifico de pesquisa bibliográfica, pesquisa de campo e pesquisa descritiva e analítica com aplicação do Diagnóstico Rural Participativo (DRP) ${ }^{1}$ em caráter individual por meio de questionários socioeconômicos, com o interesse em descobrir e observar os fatores de influência. Para alcance deste artigo utilizamos

${ }^{1} \mathrm{O}$ DRP é um termo utilizado para designar "um conjunto de métodos e abordagens que possibilitam às comunidades compartilhar e analisar sua percepção acerca de suas condições de vida, planejar e agir". Na realidade, as metodologias qualitativas de investigação se evidenciam no final da década de 1960, inspiradas nas contribuições de diferentes campos do conhecimento, como, por exemplo, (1) na chamada "Educação Libertadora" de Paulo Freire, que buscava a superação da dicotomia sujeito x objeto e teoria x prática; (2) na investigação etnográfica da Antropologia Aplicada, que se contrapunha à quantificação dos fenômenos sociais (marca do positivismo); (3) nas técnicas da análise de agroecossistemas; e (4) nas pesquisas em sistemas de produção. 


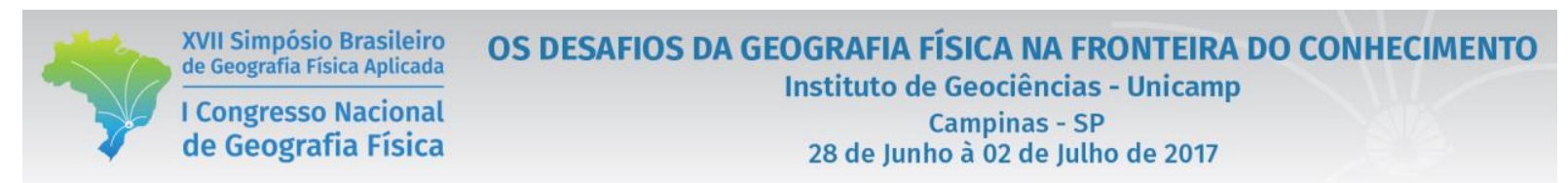

entrevistas abertas, semiestruturadas e não aleatórias. As entrevistas compreenderam o levantamento dos seguintes aspectos e informações relativas às: (a) identificação e inserção no meio físico e socioeconômico; (b) descrição e caracterização do meio natural; (c) estrutura produtiva; (d) funcionamento, dinâmica e organização do sistema de produção; (e) aspectos econômicos e financeiros; (f) resgate da trajetória histórica do uso (VASCONCELOS, 2008)

Foram feitas análises das variáveis categóricas principais versus classes das variáveis categóricas e numéricas secundárias, geraram resultados representados pelas Frequências ${ }^{2}$ e/ou percentuais das classes, possibilitando o uso deste resultado na forma de gráficos ou no formato de tabelas e quadros representativos das frequências dos resultados ou de seus valores numéricos.

Na tabela 1 podem ser observadas as variáveis secundárias (categóricas e numéricas) referentes aos aspectos socioeconômicos que foram analisadas nesta pesquisa.

Tabela I- Variáveis principais versus variáveis secundárias (categóricas e numéricas).

\begin{tabular}{l|c|l}
\hline Variável Categórica Principal & Versus & Variáveis Categórica e Numérica Secundária \\
\hline & $\mathrm{X}$ & (a) Origem, idade, membro familiares, \\
& $\mathrm{X}$ & (b) Áreas com Plantio Permanentes e \\
& $\mathrm{X}$ & Alimentares. \\
& $\mathrm{X}$ & (c) Área de Mata. \\
Unidades Familiares de Várzea & $\mathrm{X}$ & (e) Área de capoeira \\
& $\mathrm{X}$ & (f) Área de RL e APP \\
& $\mathrm{X}$ & (g) Produção \\
& $\mathrm{X}$ & (h) Receita \\
& $\mathrm{X}$ & (i) Consumo \\
& $\mathrm{X}$ & (j) Renda extra \\
\hline
\end{tabular}

Esses dados foram agrupados a partir das combinações das variáveis disponíveis que compuseram o banco de dados final por meio do programa TabWin, com planilhas formatadas no aplicativo Microsoft Office Excel. Uma matriz foi inicialmente criada, na qual as linhas representavam cada família entrevistada e as

${ }^{2}$ Número e quantidade de agricultores entrevistados, disponibilizando as informações de forma categórica ou numérica. 
colunas, as variáveis classificadas em categóricas ${ }^{3}$ e as variáveis classificadas como numéricas ${ }^{4}$. A partir dessa matriz, utilizou-se o programa TabWin para gerar arquivos com dados que foram interpretados em um aplicativo ou software de análise exploratória de dados, a fim de apresentar informações por meio de quadros ou tabulações entre as variáveis selecionadas

A análise identificou e caracterizou os diferentes extrativistas presentes na região com as combinações das informações existentes. Foram utilizadas as informações da tabela 1. Esse procedimento possibilitou a caracterização das famílias. Em seguida, foram descritas as análises referentes às variáveis da dinâmica do uso da terra, gerando tabulações representadas por quadros totalizadores, ora com o valor da frequência encontrada, ora com valor total ou somatório de valores numéricos, reconhecidos por incrementos 5 .

Após os levantamentos, os dados obtidos foram processados, utilizando-se os softwares GPS Trackmaker, para elaboração dos mapas topográficos da unidade familiar, para a análise, diagnóstico e adequação a legislação ambiental vigente. Para efeito comparativo, foram confeccionados dois mapas topográficos para cada unidade familiar: $\mathrm{O}$ primeiro, referente às áreas de acordo como as que encontramos, enquanto que a segunda foi projetada de acordo com adequações ao NCF (Lei no 12.651/2012).

De posse dos dois mapas foi feito um comparativo entre a Legislação atual e a anterior, utilizando os parâmetros determinados por cada uma delas no que se refere ao tamanho das áreas a serem destinadas para as APP e RL, etc. Posteriormente foram discutidos os impactos econômicos da produção concentrada em uma mesma área, sem que haja o avanço pelo uso de manejo inadequado nas unidades familiares. Para isso criou-se dois cenários distintos: o primeiro simula uma situação do extrativista não utilizar técnicas mínimas de manejo da cultura, o que certamente irá resultar em baixos índices de produtividade. No segundo cenário, simula-se situação inversa, na qual é incorporado manejo mínimo na produção o que, por conseguinte, maiores produtividades.

\section{Resultados e Discussão}

\footnotetext{
${ }^{3}$ Entendam-se como variáveis categóricas a associação de texto descritivo e seu valor numérico, como, por exemplo, informação sobre a escolaridade, com classes que variam de opção: primeiro grau completo assumindo valor 1 e segundo grau completo assumindo valor 2 .

4 Já as variáveis numéricas associam classes possuidoras de valores com suas respectivas unidades de medidas, como, por exemplo, informações de área do lote possuem valores de classes com intervalos que vão de 0-25 ha; e acima de 100 hectares, enquanto para outras variáveis numéricas assumem valores de classes representadas por unidades que vão de tarefas, sacos, latas, litros, entre outras medidas.

5 É a somatória dos dados, ou seja, o acumulativo das variáveis numéricas, por exemplo, o tamanho da área acumulativa de capoeirão de certo grupo comunitário.
} 




Localizada na comunidade de Monte Sião em São Domingos do Capim, a unidade familiar possui 66 hectares de extensão, representado pelo croqui (Figura 1), cujo proprietário e sua esposa e quatro de seus cinco filhos vivem do extrativismo de sua área, que apesar de que nunca acessou as linhas de crédito mais conseguem obter uma renda de aproximadamente um salário mínimo e meio. Todos possuem suas devidas documentações e todos seus filhos estudam, pois ele acredita que a educação seja a melhor forma de direcionar um homem. Assim como esposa e seus filhos também o ajudam nos afazeres da unidade familiar, a exemplo temos a catação de sementes e frutos, pesca extrativista, manejo do açaí secagem e beneficiamento das sementes, etc extraídos de sua unidade familiar que possui área produtiva dividida basicamente em: extrativismo, capoeira grossa, e áreas de manejo, principalmente de açaí (Figura 2).



Figura 1 - Apresentação da unidade familiar de várzea, com suas respectivas delimitações de subsistemas e visão panorâmica do cenário atual.

Quanto às áreas destinadas a RL possui 44 ha, representando 66,65\% de sua unidade familiar (Tabela II), porém há uma margem do leito do rio que varia de 15 a de $30 \mathrm{~m}$ de extensão sem qualquer uso de trabalho, chamado também de mata ciliar que é uma APP, conforme tabela 2

Tabela II - Apresentação das culturas dos subsistemas de terra firme e suas respectivas porcentagens dentro da área de produção da unidade familiar.

\begin{tabular}{lll}
\hline Subsistemas & Hectares (ha) & Área (\%) \\
\hline Capoeira Grossa & 2,00 & $3,04 \%$ \\
\hline
\end{tabular}




\begin{tabular}{|c|c|c|c|c|}
\hline \multirow{6}{*}{3} & \multirow{2}{*}{$\begin{array}{l}\text { XVII Simpósio Brasileiro } \\
\text { de Geografia Fisica Aplicada } \\
\text { I Congresso Nacional } \\
\text { de Geografia Física }\end{array}$} & \multirow{2}{*}{\multicolumn{3}{|c|}{$\begin{array}{l}\text { OS DESAFIOS DA GEOGRAFIA FÍSICA NA FRONTEIRA DO CONHECIMENTO } \\
\text { Instituto de Geociências - Unicamp } \\
\text { Campinas - SP } \\
28 \text { de Junho à } 02 \text { de Julho de } 2017\end{array}$}} \\
\hline & & & & \\
\hline & Area de Fl & sta & 2,00 & $3,04 \%$ \\
\hline & Reserva Le & & 44,00 & $66,65 \%$ \\
\hline & Sistemas A & gro Florestais & 18,00 & $27,27 \%$ \\
\hline & TOTAL D & IS ÁREAS & 66,00 & $100 \%$ \\
\hline
\end{tabular}

Segundo o proprietário, as espécies florestais são dispostas de maneira aleatória compõem sua unidade familiar, como o cacau (Theobroma cacao), , Cupuaçu( Theobroma grandiflorum), Bacurí (Platonia insignis), Taperebá (Spondias lutea L.), Seringa (Hevea brasiliensis), Patauá (Oneocarpus bataua), Andiroba (Carapa guianensis Aub), Bacaba (Oneocarpus bacaba), etc. Além destas, o agricultor está inserindo em sua unidade familiar espécies como Aninguapara (Dieffenbachia seguine), devido à espécie reter água no solo, facilitando o processo natural de irrigação. A área de RL e considerada um subsistema que gera receita econômica, podemos afirmar que esta se enquadra como uma fonte de renda invisível, ou seja, caso fosse representado por números iríamos constatar que possui parcela significativa na renda, assim representa $1 \%$ de sua receita, pois se houvesse uma contabilidade aproximaríamos de um investimento de 3\%, adquirindo uma lucratividade de $97 \%$ (Figura 2-A).

Vale ressaltar que a sua área de RL é preservada por consciência própria, pois este sabe da importância de conservá-las, este possui desde a sua infância, e através do seu saber empírico dá uma importância socioeconômica e ecológica preservando a floresta e todos os seus componentes florestais por acredita no bem estar que o eles proporcionam. Em sua unidade familiar encontramos outros tipos de espécies florestais, tais como: Seringueira, Andiroba, Faveira (Parkya spp.), Ingá (Inga edulis), Sumaumas (Ceiba pentandra), Goiba (Psidium guajava), Ipês (Tabebuia chysotricha), dentre outras. Esse tipo é caracterizado pela extração dos recursos naturais nas atividades da pesca, caça, coleta do açaí, coleta de vários produtos extrativistas como: lenha, cipó, breu, mel, uxi (Endopleura uchi), Caju-do-mato (Anacardium giganteum Hanck ex. Engel), Bacaba, Piquiá (Caryocar villosum) Castanha-do-pará (Bertholletia excelsa) e outros. Tais espécies representa um percentual de $1 \%$ de sua receita, cujo investimento representa 5\%, obteria lucratividade de 5\% do seu investimento, conforme (Figura 2-B). Há ainda em sua área que nunca foi explorada, também chamada de "Pirí'ou seja, área de floresta nativa, contida em 2 ha, representando 3,04\% da sua área de produção (Tabela 2), nesta área a natureza quem se encarregou de fazer toda a reprodução de espécies de animais e vegetais, sendo um ambiente totalmente preservado. E 2 ha composto por capoeira em recuperação aproximadamente a 45 anos, constituindo também 3,04\% de sua área produtiva (Tabela 2), esta por sua vez, foi opção do extrativista em não utilizála, já que ele afirma que seus 18 hectares são o suficiente para sua subsistência. 


\section{OS DESAFIOS DA GEOGRAFIA FÍSICA NA FRONTEIRA DO CONHECIMENTO \\ Instituto de Geociências - Unicamp \\ Campinas - SP \\ 28 de Junho à 02 de Julho de 2017}

Espécies como cupuaçu e cacau, foram inseridas nos seus 18 hectares de uso de terra destinado a sua renda, chamado também de SAF's, tal subsistema compõe 27,27\% de sua área de produção (Tabela 2). O cupuaçu e o cacau representam $4 \%$ e $3 \%$ de sua produtividade respectivamente, sendo que do cupuaçu há um investimento de $40 \%$, obtendo assim um total de $60 \%$ de lucro, do cacau por sua vez há um investimento de aproximadamente $30 \%$, conseguindo atingir até $70 \%$ de lucro (Figura 2-C;D), seus subprodutos são vendidos de maneira já beneficiadas em forma de polpas e bombons para que possam dessa maneira adquirir maiores valores. O açaí representa $66 \%$ da receita e é a principal renda dessa unidade familiar para adquirir tal renda é necessário um investimento de aproximadamente 30\%, chegando a alcançar 70\% lucratividade (Figura 2-E). A caça representa aproximadamente $10 \%$ de sua receita e é uma atividade praticada por todos os membros da unidade familiar para complementar alimentação, sendo geralmente feita nas margens dos igarapés, aonde os animais vão à busca de água e alimentos. As espingardas de variados calibres são os artefatos usados para efetuar a caça. É realizada durante o dia ou à noite. Durante o dia, utilizam-se cachorros e, à noite, ocorre à conhecida "espera",


paca), a cotia (Dasyprocta agouti), o tatu (Dasypus marsupiales) e o veado (Masana sp). Sua lucratividade é de aproximadamente $90 \%$, uma vez que o investimento se dá apenas pelo uso de suas espingardas e a caça é oriunda da própria natureza (Figura 2-F). A pesca representa 15\% na renda desses agricultores e tem a mesma função da caça, sendo uma atividade de subsistência para a complementação alimentar da família. A época de pesca se estende por todo o ano, sendo o verão o melhor período de captura, já que no inverno o nível da água é muito alto, dificultando a captura. Vale ressaltar que toda a mão-de-obra utilizada na pesca é do tipo familiar, assim como para a coleta de produtos oriundos da floresta e/ou na própria unidade familiar. Nesse momento, não existe qualquer nível de contratação de mão-de-obra extra para essa atividade. Por ser uma atividade artesanal, as técnicas de pescar mais frequentes são: matapi, espinhel caniço ${ }^{7}$ e malhadeira ${ }^{8}$. A pesca extrativa também é um método de uso da natureza, o rio fica a frente de sua área, tendo o livre acesso ao rio, nele há a pesca extrativista destinada apenas ao uso familiar, apesar do mínimo investimento (barco, combustível), quando aferimos a sua renda, atinge-se $90 \%$, de lucratividade (Figura 2-G).

\footnotetext{
${ }^{6}$ Uma espécie de "giral" composto por varas amarradas em árvores, geralmente perto dos alimentos (fruteiras, inajá, tatajuba, piquiá, jarana), onde o caçador fica na espera da caça;

${ }^{7}$ Apetrecho simples formado por uma linha de nylon de $2 \mathrm{~m}$ e grossura variada, amarrada em uma vara com um anzol na ponta. Serve para pescar espécies como aracu (Schizodon fasciatus), matupiri (Astyanax bimaculatus), sarda (Pellona castelnenana), anujá, acará, traíra, etc.

${ }^{8}$ Apetrecho constituído por um pano de fio de nylon branco, número 40 de $4 \times 100 \mathrm{~m}$, para capturar espécies como tucunaré (Cichla sp), pescada (Plagioscion surinamensis), arraia, surubim, filhote, piranha, pacu, anujá, acará, traíra. A malha 0,40 é para os peixes maiores e a 0,25 , para os menores.
} 




Figura 2 - Representação gráfica para cada componente inseridas nos subsistemas de produção em área de várzea.

Diante no exposto, constata-se que a unidade de várzea, segundo o NCF, o mesmo não necessita se adequar as alterações exigidas pelo novo código. Porém a não obrigação interfere diretamente no meio de produção do extrativista estudado que não possuem o conhecimento necessário para fazer o manejo mais adequado do solo, assim, cabe ao estudo em questão fazer algumas interferências nas áreas, para que estas mantenham-se enriquecidas, aumentando a produtividade ao longo dos anos e garantindo a sua reprodução familiar. Prates (2014), fazendo um reflexo sobre o novo código na agricultura familiar diz que o mesmo compromete a conservação da biodiversidade e a qualidade de água, uma vez que promoveu a redução das APPs devido os manejos dos recursos naturais. O NCF representa procedimentos que, a médio e longo prazo, podem reduzir a função socioambiental da terra e promover a insegurança alimentar.

Para tanto, o estudo sugere as seguintes proposições abaixo:

a) Nas áreas de RL, o enriquecimento com espécies frutíferas, além de resultar em maior renda familiar, aumenta a biodiversidade do meio, bem como a biomassa oriunda da matéria orgânica das espécies presentes; b) Espécies nativas com finalidade de uso de sementes para a comercialização, a exemplo da Andiroba e do Buriti, essas poderiam ter suas vendas para empresas como a Natura, de maneira mais intensificada; c) Devido ao fato do açaí ser a principal fonte de renda do extrativista, este poderia fazer 


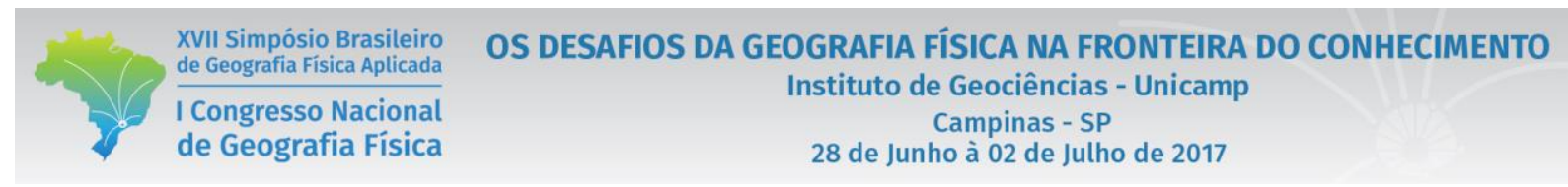

maior investimento para que seus subprodutos pudessem adquirir o selo agroecológico, aumentando com isso seu valor de mercado, subprodutos estes que poderiam ser vendidos em feiras agroecológicas. Após se inserir em cooperativas que visassem tal produção, uma vez que de fato seu produto é oriundo de um manejo isento de qualquer insumo ou produto agrotóxico. Porém para que isso aconteça, é necessário que seja instalada em sua área, fossa asséptica suspensa, uma vez que para adquirir o selo agroecológico e necessário obter qualidade fitossanitária. Exigência essa que evitaria que os dejetos humanos, depositados diretamente sobre o rio capim, retorne de alguma forma para sua área de produção através do alagamento decorrente da elevação do leito do rio; d) A área, por ser rica em frutos e sementes, pode ser utilizada para alimentação de aves, para a produção do chamado "caipirão" (aves criadas em quintal, cuja alimentação é oriunda apenas de resíduos da própria unidade familiar). Já que onerava a compra de alimentos, como o milho e a ração. Assim, pode-se também, inserir a horta suspensa para que as aves não venham a interferir no manejo; e) A pesca extrativista, muito utilizada, poderia ter adequações como a utilização de cativeiros, onerando seu tempo de pesca, e, por conseguinte levando ao consumidor, e até mesmo ao próprio agricultor, um pescado com maior qualidade de mercado, sempre verificando o período da piracema, evitando assim, que haja diminuição do pescado em sua área.

Seguindo tais projeções futuras (Figuras 3), além do aumento da sua renda, ocasiona o bem estar da unidade familiar e incentiva as unidades vizinhas a aderir a tais modificações, porém antes é necessário que os extrativistas cadastrem-se no Cadastro Rural Ambiental (CAR) para que assim ele possa se integrar as informações ambientais, de forma georreferenciada, com finalidade de controle, monitoramento, planejamento ambiental e combate ao desmatamento.



Figura 3 - Apresentação da unidade familiar de várzea, com suas respectivas delimitações de subsistemas e visão panorâmica do cenário atual, após projeção futura da utilização de sua área. 


\section{Conclusões}

O estudo demonstra o desacordo entre o código florestal em relação à situação socioeconômica e agroecológica da unidade pesquisada, visto que repor área de RL e manter APP implica em perdas produtivas. Por outro lado, já vem sendo constatando em diversos estudos que as restrições legais não têm sido suficientes para garantir a manutenção das florestas, uma vez que a maioria das unidades familiares da Amazônia já ultrapassou em 20\% o limite de desmatamento autorizado.

A aplicação de uma política ambiental (NCF) repressora de desmatamento sem uma política agrícolaextrativista contundente para viabilizar a produção em áreas já alteradas poderá inviabilizar economicamente as unidades familiares, levando este segmento a uma profunda crise social. Alguns dos motivos apontados são o tamanho de área que é incompatível com tipo de uso da terra tradicional (extrativismo) e reduzido tempo de pousio (biomassa florestal), aliada a falta de política ambiental e de motivação econômica, como o credito, assistência técnica e Pagamento de Serviços Ambientais (PSA) para levar em conta os serviços produtivos e ambientais ao decidir qual e o tipo de uso da terra a ser utilizado.

\section{Bibliografia}

MUNIZ, C. Reflexões sobre a criação e implementação do Programa Nacional de Fortalecimento da Agricultura Familiar (PRONAF). Revista Avaliação de Políticas Públicas, v. 1, n. 1, p. 91-99, jun . 2008.

OLIVEIRA, M.; BONIN, R. Entenda como pode ser a tramitação do Código Florestal no Senado. Portal G1. Brasília. 25 Mai. 2011. Política. Disponível em: <http://g1.globo.com/politica/noticia/2011/05/conhecapossibilidades-para-o-projeto-do-codigo-flrestal-no-senado.html>. Acessado em: 29 jan. 2015.

PRATES, I. Reflexo do Novo Código Florestal sobre a Agricultura Familiar: Um estudo sobre uma propriedade no município de Correntina/BA. Portal Mundo GEO. 10 Set. 2014. Disponível em: <http://mundogeo.com/blog/2014/09/10/reflexo-do-codigo-florestal-sobre-a-agricultura-familiar-um-estudo-sobreuma-propriedade-no-municipio-de-correntina-ba>. Acessado em: 05 abr. 2015.

VIANA, E. M. Reserva Legal e Área de Preservação Permanente na zona rural: um estudo da negociação entre atores em municípios do Vale do Taquari - RS. 2011. 167 f. Tese (Mestrado em Ambiente em Desenvolvimento) - Centro Universitário UNIVATES, Lajeado, 2011.

VASCONCELOS, M. A. M.; Uso da terra e manejo dos recursos naturais: Uma analise a partir do programa de política publica piloto PROAMBIENTE na região Nordeste do Estado do Pará- Brasil. Tese (Doutorado em Ciências Agrárias) - Universidade Federal Rural da Amazônia/Embrapa Amazônia Oriental, Belém, 2014. 